\title{
Assessment of safety and efficacy of mesenchymal stromal cell therapy in preclinical models of acute myocardial infarction: a systematic review protocol
}

Carly C. Barron ${ }^{1,2,3+}$, Manoj M. Lalu ${ }^{1,2,4 \dagger}$, Duncan J. Stewart ${ }^{3,6}$, Dean Fergusson ${ }^{2,5}$, Homer Yang ${ }^{1}$, David Moher ${ }^{2}$, Peter Liư ${ }^{7}$, David Mazer ${ }^{8}$, P. J. Devereaux ${ }^{9}$, Lauralyn McIntyre ${ }^{10^{*}}$ and On Behalf of the Canadian Perioperative Anesthesia Clinical Trials Group

\begin{abstract}
Background: Despite advances in treatment, acute myocardial infarction (MI) is still associated with significant morbidity and mortality, especially in patients with extensive damage and scar formation. Based on some promising preclinical studies, there is interest in the use of mesenchymal stromal cells (MSCs) to promote cardiac repair after acute MI. However, there is a need for a systematic review of this evidence to summarize the efficacy and safety of MSCs in preclinical models of MI. This will better inform the translation of MSC therapy for acute MI and guide the design of a future clinical trial.

Methods/design: A systematic literature search of MEDLINE, Embase, and BIOSIS Previews will be conducted. We will identify comparative preclinical studies (randomized and non-randomized) of myocardial infarction that include animals given MSC therapy versus a vehicle/placebo. The primary outcome will be left ventricular ejection fraction. Secondary and tertiary outcomes will include death, infarct size, measures of cardiac function, biochemical outcomes, and MSC retention and differentiation. Risk of bias will be assessed using the Cochrane Risk of Bias Tool. Subgroup analyses will be performed to measure how various sources of preclinical study heterogeneity affect the direction and magnitude of the primary outcome. We will meta-analyze data using inverse variance random effects modeling.

Discussion: This systematic review of preclinical evidence will provide a summary of the efficacy and safety of MSCs in animal models of Ml. The results will help determine whether sufficient evidence exists to conduct a clinical trial in humans and inform its design.
\end{abstract}

Keywords: Mesenchymal stromal cells, Mesenchymal stem cells, Perioperative myocardial infarction, Myocardial infarction, Preclinical, Systematic review protocol

\section{Background}

Cardiovascular disease is the leading cause of mortality in the western world [1]. Acute myocardial infarction (MI) can lead to permanent loss of cardiomyocytes and scar tissue formation and, in the event of a large area of

\footnotetext{
* Correspondence: Imcintyre@ottawahospital.on.ca; Imcintyre@ohri.ca ${ }^{\dagger}$ Equal contributors

${ }^{10}$ Clinical Epidemiology Program, Ottawa Hospital Research Institute, Department of Medicine (Division of Critical Care), University of Ottawa, 501 Smyth Rd, Box 201, Ottawa, ON K1H 8L6, Canada

Full list of author information is available at the end of the article
}

injury, may result in heart failure and life-threatening arrhythmia. Despite advances in treatment such as coronary revascularization, some MI patients are left with extensive cardiac damage and a poor prognosis, highlighting the need to develop novel therapies to repair nonfunctional myocardium.

Over the past decade, mesenchymal stromal cells (MSCs) - also known as adult stem cells, marrow stromal cells, or mesenchymal stem cells-have emerged as a potential new therapy for acute MI. These cells can be isolated from a variety of tissues including bone marrow, adipose 
tissue, and the umbilical cord and (because they appear to be relatively immune privileged) can be subsequently delivered as an allogeneic product to patients [2]. In individual studies using preclinical models of acute MI, MSCs have been demonstrated to augment tissue repair, improve cardiac function [3], dampen the inflammatory response [4], and potentially reduce mortality [5]. However, these preclinical studies have not been systematically summarized to examine the efficacy of these cells in acute MI. Members of our group and others have demonstrated that MSC therapy acts via a myriad of paracrine pathways to dampen inflammation and augment cytoprotection [6-8]. Moreover, MSCs can improve cellular energetics by transferring mitochondria [9]. This is unlike drug-based therapeutics which largely act via "lock-and-key" mechanisms in which a specific substrate binds to a single active site matching its structure.

We are particularly interested in perioperative MI, which is an MI that occurs in the setting of inflammation and increased oxygen consumption induced by surgery [10, 11]. Perioperative $\mathrm{MI}$ is associated with poor outcomes, including a 30 -day mortality of $\sim 12 \%$ (vs. $2 \%$ for postsurgical patients without perioperative MI) [12]. Given the cytoprotective effects of MSCs, they may be particularly beneficial in the highly pro-inflammatory and catabolic setting of perioperative MI (see Fig. 1). Prior to considering a first-in-human clinical trial of MSC therapy for perioperative MI, we propose a comprehensive synthesis of the published literature. These data will determine whether additional evidence gaps remain to warrant further preclinical work, as well as future directions of MI research.

The specific aims of this systematic review are as follows:

1. To systematically compare the efficacy and safety of MSC therapy versus control in preclinical MI. Our primary outcome is left ventricular ejection fraction. Secondary endpoints include death, other measures of cardiac function, inflammatory markers, and vessel density. Tertiary endpoints will include cellular retention and differentiation.

2. Threats to internal validity will be evaluated using a modified version of the Cochrane Risk of Bias Tool for preclinical studies [13]. We will determine whether risk of bias influences the magnitude and direction of the primary endpoint.

3. External validity will be evaluated using subgroup analyses to measure how various sources of preclinical study heterogeneity (e.g., type of MI model, animal species, severity of MI) affect the direction and magnitude of the primary outcome.

4. Construct validity will be examined to evaluate the degree preclinical studies of MSC therapy for MI incorporate elements of clinical perioperative MI

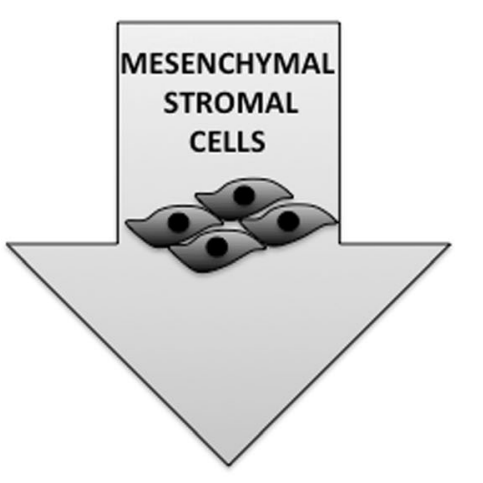

Inhibition of pro-inflammatory cytokine production

Anti-apoptosis

Secretion of cytoprotective factors

Maintenance of endothelial integrity

Stimulation of angiogenesis

Mitochondrial transfer and improved cellular energetics

Inhibition of cardiac fibroblasts and remodeling

Production of pro-inflammatory cytokines (ie. INF-Y, TNF- $\alpha$, IL-1 $\beta$, IL-6)

Apoptosis

Tissue damage

Myocardial dysfunction

Left ventricle remodeling

Impaired ejection fraction

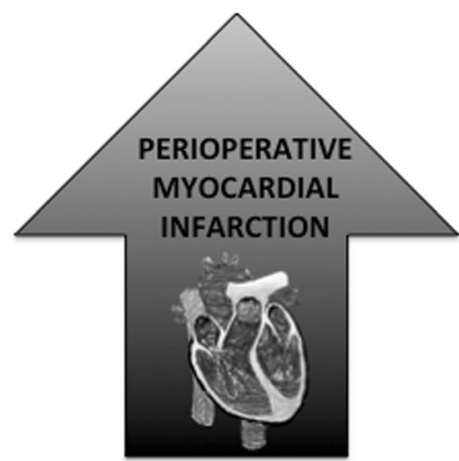

Fig. 1 Therapeutic mechanisms of mesenchymal stromal cells in myocardial infarction 
(e.g., pathophysiological elements), as this will be the focus of our future clinical trial.

\section{Methods and design Protocol}

This systematic review protocol is reported in accordance with the Preferred Reporting Items for Systematic Review and Meta-Analysis Protocols (PRISMA-P) reporting guidelines [14]. A summary of the protocol will be listed on the Collaborative Approach to Meta-Analysis and Review of Animal Data from Experimental Studies (CAMARADES) website (http://www.camarades.info). The final review will be reported using the PRISMA guidelines [15].

\section{Data sources}

We will search the following databases Ovid MEDLINE', Ovid MEDLINE ${ }^{\bullet}$ In-Process \& Other Non-Indexed Citations, Embase Classic + Embase, and BIOSIS. In addition, a manual review of the bibliographies of selected articles (e.g., reviews) will be performed.

\section{Search strategy}

Search strategies will be developed by our research team in collaboration with an information specialist. Prior to final implementation, all strategies will undergo Peer Review of Electronic Search Strategies (PRESS) by another senior information specialist $[16,17]$. Search strategies will use controlled vocabulary (e.g., Mesenchymal Stromal Cells) and keywords (e.g., MSCs) with adjustment for each database. We will apply preclinical filters to increase search efficiency [18-20]. Duplicate citations will be removed. The example search strategy (see Additional file 1) was used to search in MEDLINE.

\section{Eligibility criteria}

Eligible studies include controlled comparative studies of preclinical MI or cardiac ischemia-reperfusion injury. We will include studies in which true randomization is performed using a method with a low risk of selection bias (such as computer random number generators and random number tables), as well as those that are quasi-randomized (i.e., by day of week or alternation) and non-randomized. This broad range of comparative studies will be included in order to answer our study question as terminology and methodology that is commonplace in clinical studies is not routinely employed in preclinical studies, and previous reviews have shown that randomization is reported in a third or less of animal studies [21]. Only peer-reviewed publications will be eligible with no restriction to publication year.

\section{Population}

We will include all preclinical in vivo models of experimentally induced MI that mimic pathophysiological aspects of clinical MI (see Table 1). Included studies will be
Table 1 Preclinical models of perioperative myocardial infarction $^{\mathrm{a}}$

\begin{tabular}{|c|c|}
\hline Class & Example \\
\hline $\begin{array}{l}\text { Ligation of the left } \\
\text { coronary artery }\end{array}$ & Open chest, closed chest \\
\hline Ischemia-reperfusion & Global ischemia-reperfusion model \\
\hline Cryoinjury & $\begin{array}{l}\text { Liquid nitrogen cooled copper probe used to } \\
\text { injure coronary vessel }\end{array}$ \\
\hline Microembolism & $\begin{array}{l}\text { Injection of automicrothrombotic particulates } \\
\text { into coronaries }\end{array}$ \\
\hline Electrocauterisation & Direct electorcauterization of a coronary vessel \\
\hline $\begin{array}{l}\text { Pharmacological } \\
\text { induction }\end{array}$ & Isoproterenol \\
\hline Genetic model & $\begin{array}{l}\text { Watanabe heritable hyperlipidemic rabbits with } \\
\text { acute induced infarction }\end{array}$ \\
\hline
\end{tabular}

${ }^{\mathrm{a} A l l}$ included models must provide an anesthetic either pre-induction or concurrent with the induction of myocardial infarction

perioperative (i.e., anesthetic provided before or concurrent to acute MI). In vitro studies, ex vivo studies, and neonatal MI models will be excluded.

\section{Intervention}

Studies using MSCs will be included; the International Society of Cellular Therapy consensus statement defining criteria for MSCs will be used as a guide [22]. We will include MSCs from xenogeneic, syngeneic, or allogeneic sources of any tissue origin. All delivery routes, including direct myocardial injection, intravenous and intra-arterial, will be considered. To be eligible, MSCs must be administered as a pretreatment or no later than 7 days following the induction of MI. This timing has been chosen to reflect the possible interventional window for a perioperative clinical trial.

Our focus will be on non-manipulated cells as this will be the intervention in a potential future trial. We will exclude differentiated MSCs (e.g., differentiated into a myocyte), genetically engineered MSCs, and MSCs administered by a scaffold system. Studies using MSCs only modified for cellular identification (e.g., reporter gene systems or nanoparticles) will be included. We will also exclude studies that investigate another novel agent as a co-treatment.

\section{Comparator}

All studies with a control arm of animals that have had experimental MI or cardiac ischemia-reperfusion injury (diseased control animals) induced and were treated with placebo/vehicle will be included.

\section{Outcomes}

\section{Primary endpoint}

Left ventricular ejection fraction (LVEF), measured as a continuous variable at specific time points after MSC or control intervention, will be the primary endpoint. LVEF is 
a clinically meaningful endpoint since it has been linked to mortality following MI [23]. Physiologically, LVEF determines stroke volume, which together with heart rate determines cardiac output. It is also a feasible outcome as it is the most commonly reported cardiac function measure in preclinical studies [24, 25]. Various techniques are used to measure LVEF including two- or three-dimensional echocardiography, magnetic resonance imaging, and computed tomography. In our review, we will include and describe all techniques of LVEF measurement.

\section{Secondary outcomes}

Secondary outcomes will be a combination of dichotomous and continuous measures. A detailed listing of secondary/ tertiary outcomes is provided in Table 2. Given the large number of outcomes, these results will be considered exploratory and interpreted cautiously. Secondary endpoints will include measures of cardiac function by

Table 2 A priori defined secondary and tertiary outcome measures

\begin{tabular}{|c|c|}
\hline Outcomes & Comments and/or Examples of specific measures \\
\hline \multicolumn{2}{|c|}{ Secondary outcomes: } \\
\hline Death & $\begin{array}{l}\text { Rarely used an outcome due to ethical concerns } \\
\text { regarding animal welfare }\end{array}$ \\
\hline Infarct size & $\begin{array}{l}\text { Variety of quantifiable techniques (e.g. histological } \\
\text { staining, nuclear imaging) }\end{array}$ \\
\hline \multirow{11}{*}{$\begin{array}{l}\text { Cardiac } \\
\text { function }\end{array}$} & Echocardiography \\
\hline & cardiac output \\
\hline & left ventricle end diastolic diameter \\
\hline & left ventricle end systolic diameter \\
\hline & fractional shortening \\
\hline & Cardiac catheterization \\
\hline & cardiac output \\
\hline & left ventricular end diastolic pressure \\
\hline & left ventricular end systolic pressure \\
\hline & mean pulmonary artery pressure \\
\hline & right atrial pressure \\
\hline \multirow{6}{*}{$\begin{array}{l}\text { Biochemical } \\
\text { outcomes }\end{array}$} & Proinflammatory cytokines \\
\hline & interleukin-1 beta, 6 \\
\hline & tumour necrosis factor-alpha \\
\hline & Anti-inflammatory cytokines \\
\hline & interleukin-10 \\
\hline & transforming growth factor-beta1, 2, 3 \\
\hline Vessel density & $\begin{array}{l}\text { Histological staining and quantification of vessels in } \\
\text { cardiac tissue }\end{array}$ \\
\hline \multicolumn{2}{|c|}{ Tertiary outcomes: } \\
\hline $\begin{array}{l}\text { Cellular } \\
\text { retention }\end{array}$ & $\begin{array}{l}\text { Imaging and quantification of labelled cells in host } \\
\text { tissue }\end{array}$ \\
\hline $\begin{array}{l}\text { Cellular } \\
\text { differentiation }\end{array}$ & $\begin{array}{l}\text { Measurement of cardiac troponin in donor cells } \\
\text { retained in host tissue }\end{array}$ \\
\hline
\end{tabular}

echocardiography (e.g., cardiac output, fractional shortening, left ventricle end diastolic diameter, left ventricle end systolic diameter) and cardiac catheterization (e.g., left ventricular end diastolic pressure, left ventricular end systolic pressure, mean pulmonary artery pressure, right ventricular systolic pressure), biochemical outcomes (e.g., cytokines), infarct size, and vessel density. These measurements will provide additional support as to whether MSCs preserve ventricular function and prevent the pathological remodeling that occurs after MI. Furthermore, data on biochemical markers will help elucidate the role MSC therapy plays in regulating cellular and molecular mechanisms involved in the pro-inflammatory state following MI. Death will also be recorded; however, few studies use this endpoint due to considerations for animal welfare [26]. The occurrence of adverse events/negative effects with MSC administration will be recorded.

\section{Tertiary outcomes}

Tertiary endpoints will include MSC retention and differentiation (see Table 2). While our primary and secondary endpoints focus on measures that evaluate the efficacy of MSCs, the homing and potential differentiation of MSCs in myocardial tissue is also of interest.

\section{Timing}

The primary outcome of left ventricle ejection fraction and secondary biochemical outcomes and death will be collected at baseline, $<6 \mathrm{~h}, 6-24 \mathrm{~h},>24-72 \mathrm{~h},>72 \mathrm{~h}-$ 1 week, $>1-3$ weeks, $>3-4$ weeks, and $>4$ weeks after the administration of MSCs versus controls. These detailed intervals reflect the evolution of inflammation and remodeling in MI, described by our group and others [27-31]. In preclinical models of myocardial infarction, robust increases in expression of cytokines such as TNF- $\alpha$, IL- $1 \beta$, and IL- 6 have been noted immediately after myocardial injury and up to $24 \mathrm{~h}$ later [32]. This is followed by a chronic remodeling phase in which cardiomyocytes are replaced by granulation tissue and a scar is formed at the infarct. Scar formation has been demonstrated by approximately day 14 post-infarct in mice, while a canine infarct is still evolving at this time point [29]. Therefore, our prespecified time intervals will capture outcomes during the post-infarct inflammatory response and repair of cardiac function in both small and large animal models of MI. All other secondary outcomes of cardiac function and tertiary outcomes of retention and engraftment will be collected at the latest time point, $>4$ weeks after administration, to capture these measurements after the proinflammatory state and repair has occurred.

\section{Study selection and data extraction}

Studies will be screened independently by two reviewers using dedicated cloud-based software (DistillerSR, Evidence 
Partners, Ottawa, Canada). Using the previously described a priori inclusion criteria, first level screening (title/abstract) will be liberal with both reviewers needed to exclude an article and one reviewer needed to include. We will be using an accelerated screening method for the title and abstracts in which the second reviewer will review records excluded by the first reviewer [33]. Second level screening (full study) will be performed independently in duplicate. If there are disagreements, the two individuals involved will review the case. If they cannot come to an agreement, a senior team member will provide the final decision. Reasons for exclusion will be recorded to enable a transparent selection process $[34,15]$.

Information from included studies will be collected on electronic data extraction forms. General categories include study characteristics (e.g., design), study population (e.g., species), MI model (e.g., cryoinjury), intervention and comparison (e.g., MSC dose), co-interventions (e.g., immunosuppressants, antibiotics, and cardiac medications), and preclinical outcomes (e.g., ejection fraction). Data extraction forms will be prepared a priori, and a calibration exercise will pilot five studies to refine the forms and ensure inter-rater consistency. Examples of data collection elements can be seen in Table 3 .

\section{Risk of bias assessment}

As there is no validated tool to assess risk of bias in animal studies, we will describe potential biases using a modified version of The Cochrane Risk of Bias Assessment Tool [13]. Items include concealment of allocation, random sequence generation, blinding of personnel and endpoint measurements, and completeness of endpoint reporting. We will include additional domains relevant to animal studies such as source of funding, conflict of interest, sample size calculations, similarity of groups or adjustment for confounders at baseline, random housing of animals, and animal selection at random for outcome assessment. Risk of bias assessment will be carried out in duplicate by two independent reviewers. Disagreements will be resolved using the same process listed above. Each criterion will be assigned a value of low, high, or unclear risk of bias for each included study. A summary for all included studies will be presented in a table format. We have planned an analysis to determine the effects of high vs. low risk of bias on the effect size of the primary outcome.

\section{Assessment of external and construct validity}

In preclinical studies, external validity describes the ability to generalize findings to different experimental conditions. External validity will be assessed by subgroup analysis of the primary outcome based on species, strain, age, sex, presence of intercurrent illness, MI model, ischemic time (if an ischemia-reperfusion model), MSC source (animal/tissue), timing of MSC administration (pretreatment vs. rescue)
Table 3 A priori defined data collection elements

\begin{tabular}{ll}
\hline $\begin{array}{l}\text { Data collection } \\
\text { element }\end{array}$ & Items \\
\hline Study & Author \\
& Year of publication \\
& Funding support \\
& Country \\
& Study design \\
& Total number of animals used \\
& N per independent intervention group \\
& Species \\
& Strain \\
& Gender \\
& Weight \\
& Mean age \\
& MI model (i.e. LAD ligation, ischemia reperfusion, \\
& cryoinjury, microembolism) \\
Intercurrent illness of animal & Anesthetic administered \\
Route of MSC delivery (intravenous, intracoronary, \\
intramyocardial) \\
Timing of MSC delivery \\
Frequency of MSC delivery \\
Source of MSCs (syngenic, allogeneic, xenogenic) \\
Tissue origin of MSCs (bone marrow, adipose, \\
Wharton's jelly) \\
Condition of MSCs (fresh, cryopreserved) \\
Vehicle \\
Defining criteria for MSCs \\
\end{tabular}

administration route, type of control, use of co-interventions (antibiotic, immunosuppressant, antihypertensive, statin, $\beta$ blocker, antiplatelet, anticoagulant therapies, all yes vs. no), and single versus multicenter study. Given the large number of analyses planned, they will be used in an exploratory manner and the results interpreted with caution. Examining the effect of differences in experimental design will inform aspects of a future clinical trial.

In preclinical studies, construct validity refers to the extent an animal model corresponds to the clinical entity it is intended to represent [35]. Construct validity will be assessed in relation to the extent the experimental systems model the clinical entity of perioperative MI using a framework based on expert opinion (see Table 4). It will help determine whether the included studies enable reliable causal inference and generalization to a potential clinical study of MSCs for perioperative MI.

\section{Strategy for data synthesis}

Search results will be presented in a PRISMA study flow diagram [15]. Categorical variables will be summarized by 
Table 4 Checklist of construct validity for preclinical perioperative myocardial infarction (PeriopMI)

\begin{tabular}{|c|c|c|c|c|}
\hline $\begin{array}{l}\text { Construct } \\
\text { validity } \\
\text { domain }\end{array}$ & $\begin{array}{l}\text { Criteria from } \\
\text { guidelines } \mathrm{s}^{\mathrm{a}, \mathrm{b}}\end{array}$ & $\begin{array}{l}\text { Specific } \\
\text { application to } \\
\text { PeriopMl }\end{array}$ & Justification & $\begin{array}{l}\text { Yes/ } \\
\text { No }\end{array}$ \\
\hline \multirow[t]{2}{*}{$\begin{array}{l}\text { Animal } \\
\text { Subjects }\end{array}$} & $\begin{array}{l}\text { Matching } \\
\text { model to age } \\
\text { of patients in } \\
\text { clinical setting }\end{array}$ & $\begin{array}{l}\text { Middle aged to } \\
\text { elderly animal } \\
\text { model used }\end{array}$ & $\begin{array}{l}\text { Incidence of } \\
\text { PeriopMl } \\
\text { increases over } \\
\text { age 50; age } \\
>75 \text { is an } \\
\text { independent } \\
\text { risk factor for } \\
\text { PeriopMl [46] }\end{array}$ & \\
\hline & $\begin{array}{l}\text { Matching } \\
\text { model to co- } \\
\text { morbidities in } \\
\text { clinical setting }\end{array}$ & $\begin{array}{l}\text { Animal model } \\
\text { has } \geq 1 \text { co- } \\
\text { morbidity risk } \\
\text { factor for } \\
\text { PeriopMl, either } \\
\text { chronic or } \\
\text { acute (e.g. } \\
\text { atherosclerosis, } \\
\text { diabetes, } \\
\text { chronic kidney } \\
\text { disease, } \\
\text { hypotension, } \\
\text { acute blood } \\
\text { loss) }\end{array}$ & $\begin{array}{l}\text { Co-morbidities } \\
\text { listed are } \\
\text { independent } \\
\text { risk factors for } \\
\text { PeriopMI [47] }\end{array}$ & \\
\hline $\begin{array}{l}\text { Outcome } \\
\text { Measures }\end{array}$ & $\begin{array}{l}\text { Matching of } \\
\text { outcome } \\
\text { measure to } \\
\text { clinical setting }\end{array}$ & $\begin{array}{l}\text { Late outcome } \\
\text { measures } \\
\text { performed (e.g. } \\
>3 \text { weeks } \\
\text { when scar } \\
\text { formation and } \\
\text { acute changes } \\
\text { are complete) }\end{array}$ & $\begin{array}{l}\text { A longer } \\
\text { follow-up } \\
\text { duration may } \\
\text { reflect chronic } \\
\text { effects of an } \\
\text { acute therapy } \\
\text { for PeriopMl }\end{array}$ & \\
\hline \multirow[t]{2}{*}{$\begin{array}{l}\text { Modeling of } \\
\text { Disease }\end{array}$} & $\begin{array}{l}\text { Matching } \\
\text { model to } \\
\text { human } \\
\text { manifestation } \\
\text { of disease }\end{array}$ & $\begin{array}{l}\text { Model reflects } \\
\text { elements of } \\
\text { Type } 1 \text { MI (e.g. } \\
\text { plaque rupture) } \\
\text { and/or Type } 2 \\
\text { (e.g. supply } \\
\text { demand } \\
\text { imbalance) }\end{array}$ & $\begin{array}{l}\text { Clinical PeriopMl } \\
\text { displays aspects } \\
\text { of Type } 1 \text { and } \\
\text { Type } 2 \text { Ml [30, } \\
\text { 42] }\end{array}$ & \\
\hline & & $\begin{array}{l}\text { A pro- } \\
\text { inflammatory } \\
\text { state is } \\
\text { reported }\end{array}$ & $\begin{array}{l}\text { Clinical } \\
\text { PeriopMI has a } \\
\text { large } \\
\text { inflammatory } \\
\text { burden [19] }\end{array}$ & \\
\hline $\begin{array}{l}\text { Administration } \\
\text { of Intervention }\end{array}$ & $\begin{array}{l}\text { Treatment } \\
\text { response } \\
\text { along } \\
\text { mechanistic } \\
\text { pathway }\end{array}$ & $\begin{array}{l}\text { Therapy given as } \\
\text { a pretreatment } \\
\text { (i.e. preventative) } \\
\text { or within the first } \\
48 \mathrm{~h} \text { after } \\
\text { anesthesia }\end{array}$ & $\begin{array}{l}\text { Majority of } \\
\text { PeriopMl } \\
\text { occurs within } \\
\text { the first } 48 \mathrm{~h} \\
\text { after surgery }\end{array}$ & \\
\hline Environment & $\begin{array}{l}\text { Address } \\
\text { confounds } \\
\text { associated } \\
\text { with setting, } \\
\text { experimental } \\
\text { setting }\end{array}$ & $\begin{array}{l}\text { Post-operative } \\
\text { analgesia } \\
\text { provided }\end{array}$ & $\begin{array}{l}\text { Inadeqaute } \\
\text { post-operative } \\
\text { analgesia } \\
\text { increases } \\
\text { systemic } \\
\text { inflammation }\end{array}$ & \\
\hline
\end{tabular}

Abbreviations: $\mathrm{MI}$ myocardial infarction, PeriopMI perioperative myocardial infarction

${ }^{\mathrm{a}}$ Recommendations to reduce threats to construct validity were identified by Henderson et al. [19]

${ }^{\mathrm{b}}$ Construct validity criteria suggested by $\geq 40 \%$ of included guidelines included in checklist frequencies/percentages, and continuous variables will be summarized by means and standard deviations or median and interquartile ranges, depending on data distribution.

Dichotomous endpoints (e.g., death) from each included study will be pooled and described as odds ratios and 95\% confidence intervals. Results from outcomes with discrete data will be pooled, and meta-analysis will be performed with inverse variance random effects modeling. Continuous endpoints will be pooled using the ratio of weighted means method with inverse variance random effects modeling [36]. Ratio of means allows for pooling of outcomes expressed in different units and comparisons of effect sizes across interventions. As ratio of means is well suited for the small sample sizes of animal studies, and provides a result in a form similar to a risk ratio, we have chosen this method because of its simplified clinical interpretation. Statistical heterogeneity will be examined using $I^{2}$ tests with 95\% uncertainty intervals [37]. Planned sensitivity analyses will examine heterogeneity of the primary outcome. These will be carried out according to risk of bias assessments. Selective outcome reporting will be assessed using the excess significance test (comparing the expected percentage of significant results vs. actual reported effects) [38]. An evaluation for the presence of publication bias will be conducted with funnel plot techniques and Egger's regression test [39].

\section{Knowledge translation}

Several knowledge users of the results of this systematic review have been identified. These include the Canadian Perioperative Anesthesia Clinical Trials (PACT) Group, a network of academic perioperative medicine researchers that develop team-based approaches to investigate perioperative clinical and basic science questions (www.canadianpact.ca). Our other knowledge users include the Canadian Council on Animal Care, Canadian Society for Atherosclerosis Thrombosis, and Vascular Biology (www.csatvb.ca) and the Stem Cell Foundation of Canada (www.stemcellfoundation.ca). Through these users, our research will reach key perioperative researchers, preclinical and translational scientists, and health professionals as well as the lay community.

This work will identify gaps in the current knowledge of MSC therapy of MI. Publication of our results will also identify potential future directions of MSC for MI research as they specifically relate to perioperative MI. Most importantly, the publication of key findings of the review and meta-analysis will directly inform a potential clinical trial.

\section{Discussion}

This review proposes to systematically identify and summarize preclinical evidence that exists regarding MSC therapy in myocardial infarction models, using a rigorous methodology. We will assess the effect of MSC 
therapy on clinically important outcomes including cardiac function, infarct size, inflammation, and death.

In our pilot searches, we have identified two published preclinical reviews that investigated stem cells in both acute and chronic ischemia models [24, 25]. Our proposed preclinical review differs significantly from these studies in several respects. Both previous studies combined results from various stem cell types and were restricted to large animal models, whereas our review will focus on MSCs and consider both small and large animal models. The search strategies used in these papers identified 39 studies that used MSCs; however, based on our pilot search using a comprehensive strategy, we have identified approximately 200 studies to be included in our review. Most importantly, the data from these reviews included cell therapy for chronic heart failure (48\% of studies); therapy of established chronic heart failure has little construct validity for the acute treatment of MI. Thus, our review will provide novel evidence to determine if a clinical study of MSCs for MI is warranted.

Given that less than 5\% of high impact preclinical reports are clinically translated [40] and only $11 \%$ of clinically tested agents receive licensing, rigorous appraisal of preclinical data is needed prior to clinical testing of novel therapeutics. Historically, failed translation (preclinical to clinical) of specific therapies for stroke [41] and heart failure [42] could have been predicted by systematic reviews of animal data. Thus, our review is critical prior to conducting a resource intensive trial.

Furthermore, since the design of these preclinical studies wil include administration of anesthetic and disease induction that likely differs from spontaneous MI, this review also provides a unique opportunity to determine if MSCs may have efficacy in clinical perioperative MI. This question is of particular interest to our group as therapies that are effective in prevention of nonoperative MI have failed to show benefit in perioperative MI [43-45] and there are currently few therapies for established perioperative MI. Given what is known about the mechanism of action of MSCs, they may be highly effective in the pro-inflammatory state that occurs with perioperative MI.

In summary, this review will be the first to provide an estimate of efficacy and safety of MSC therapy in preclinical models of MI. This will ultimately help determine whether sufficient evidence exists to support a first-in-human evaluation of MSC therapy for perioperative MI. Additionally, the results of this study will identify knowledge gaps and potential future areas of study in MI research.

\section{Additional file}

Additional file 1: Description: representative search strategy. (DOCX 13 kb)

\section{Abbreviations}

LVEF: Left ventricular ejection fraction; MI: Myocardial infarction; MSCs: Mesenchymal stromal cells

\section{Acknowledgements}

CB was funded by a Faculty of Medicine Canadian Institutes of Health Research Summer Studentship and an Undergraduate Research Opportunity Award both from the University of Ottawa, ON, Canada.

MML was a post-doctoral fellow supported by the Heart and Stroke Foundation of Canada and The Ottawa Hospital Anesthesia Alternate Funds Association. We thank Risa Shorr (Librarian and Information Specialist, The Ottawa Hospital, Ottawa, ON, Canada) for providing assistance with the generation of a systematic search strategy.

\section{Funding}

This work received no external funding.

\section{Availability of data and materials \\ Not applicable}

\section{Authors' contributions}

$M M L, L M$, and $C C B$ conceived the study design and were responsible for the initial drafting and manuscript revisions. DJS, DF, HY, DMo, PL, DMa and PJD provided critical feedback for protocol development and the final manuscript. MML is the guarantor of the review. All authors read and approved the final manuscript.

Ethics approval and consent to participate

Not applicable.

\section{Consent for publication}

Not applicable.

\section{Competing interests}

David Moher is the chief editor of Systematic Reviews. Duncan Stewart is the President CEO of Northern Therapeutics. The remaining authors have no competing interests to declare.

\section{Publisher's Note}

Springer Nature remains neutral with regard to jurisdictional claims in published maps and institutional affiliations.

\section{Author details}

'Department of Anesthesiology and Pain Medicine, The Ottawa Hospital, Ottawa, Canada. ${ }^{2}$ Blueprint Translational Research Group, Clinical Epidemiology Program, Ottawa Hospital Research Institute, Ottawa, Canada. ${ }^{3}$ Department of Medicine, McMaster University, Hamilton, Canada.

${ }^{4}$ Regenerative Medicine Program, Ottawa Hospital Research Institute, Ottawa, Canada. ${ }^{5}$ Department of Epidemiology \& Community Medicine, University of Ottawa, Ottawa, Canada. ${ }^{6}$ Department of Cell and Molecular Medicine, University of Ottawa, Ottawa, Canada. ${ }^{7}$ The Ottawa Heart Institute, Ottawa, Canada. ${ }^{8}$ Department of Anesthesia, St. Michael's Hospital, University of Toronto, Toronto, Canada. ${ }^{9}$ Population Health Research Institute, David Braley Cardiac, Vascular, and Stroke Research Institute, McMaster University, Hamilton, Canada. ${ }^{10}$ Clinical Epidemiology Program, Ottawa Hospital Research Institute, Department of Medicine (Division of Critical Care), University of Ottawa, 501 Smyth Rd, Box 201, Ottawa, ON K1H 8L6, Canada.

Received: 16 November 2016 Accepted: 2 October 2017

Published online: 07 November 2017

\section{References}

1. Writing Group Members, Mozaffarian D, Benjamin EJ, et al. Heart disease and stroke statistics-2016 update: a report from the American Heart Association. Circulation. 2016;133:e38-60.

2. Lalu MM, McIntyre L, Pugliese C, et al. Safety of cell therapy with mesenchymal stromal cells (SafeCell): a systematic review and meta-analysis of clinical trials. PLoS One. 2012;7:e47559.

3. Cashman TJ, Gouon-Evans V, Costa KD. Mesenchymal stem cells for cardiac therapy: practical challenges and potential mechanisms. Stem Cell Rev. 2013;9:254-65. 
4. van den Akker F, Deddens JC, Doevendans PA, et al. Cardiac stem cell therapy to modulate inflammation upon myocardial infarction. Biochim Biophys Acta. 2013;1830:2449-58.

5. Llano R, Epstein S, Zhou R, et al. Intracoronary delivery of mesenchymal stem cells at high flow rates after myocardial infarction improves distal coronary blood flow and decreases mortality in pigs. Catheter Cardiovasc Interv. 2009;73:251-7.

6. dos Santos CC, Murthy S, Hu P, et al. Network analysis of transcriptional responses induced by mesenchymal stem cell treatment of experimental sepsis. Am J Pathol. 2012;181:1681-92.

7. Mei SH, Haitsma JJ, Dos Santos CC, et al. Mesenchymal stem cells reduce inflammation while enhancing bacterial clearance and improving survival in sepsis. Am J Respir Crit Care Med. 2010;182:1047-57.

8. Togel F, Weiss K, Yang Y, et al. Vasculotropic, paracrine actions of infused mesenchymal stem cells are important to the recovery from acute kidney injury. Am J Physiol Renal Physiol. 2007;292:F1626-35.

9. Jackson MV, Morrison TJ, Doherty DF, et al. Mitochondrial transfer via tunneling nanotubes is an important mechanism by which mesenchymal stem cells enhance macrophage phagocytosis in the in vitro and in vivo models of ARDS. Stem Cells. 2016;34:2210-23.

10. Landesberg G, Beattie WS, Mosseri M, et al. Perioperative myocardial infarction. Circulation. 2009;119:2936-44.

11. Thygesen K, Alpert JS, Jaffe AS, et al. Third universal definition of myocardial infarction. Glob Heart. 2012;7:275-95.

12. Devereaux PJ, Sessler DI. Cardiac complications in patients undergoing major noncardiac surgery. N Engl J Med. 2015;373:2258-69.

13. Higgins JP, Altman DG, Gotzsche PC, et al. The Cochrane Collaboration's tool for assessing risk of bias in randomised trials. BMJ. 2011;343:d5928.

14. Moher $D$, Shamseer $L$, Clarke $M$, et al. Preferred reporting items for systematic review and meta-analysis protocols (PRISMA-P) 2015 statement. Syst Rev. 2015;4:1,4053-4-1.

15. Moher D, Liberati A, Tetzlaff J, et al. Preferred reporting items for systematic reviews and meta-analyses: the PRISMA statement. Int J Surg. 2010;8:336-41.

16. McGowan J. An evidence based checklist for the Peer Review of Electronic Search Strategies (PRESS EBC). Evid Based Libr Inf Pract. 2010;5(1):149.

17. Sampson M, McGowan J, Cogo E, et al. An evidence-based practice guideline for the peer review of electronic search strategies. J Clin Epidemiol. 2009;62:944-52.

18. de Vries RB, Hooijmans CR, Tillema A, et al. A search filter for increasing the retrieval of animal studies in Embase. Lab Anim. 2011:45:268-70.

19. Hooijmans CR, Tillema A, Leenaars $M$, et al. Enhancing search efficiency by means of a search filter for finding all studies on animal experimentation in PubMed. Lab Anim. 2010;44:170-5.

20. Leenaars $M$, Hooijmans $C R$, van Veggel $N$, et al. A step-by-step guide to systematically identify all relevant animal studies. Lab Anim. 2012;46:24-31.

21. van der Worp HB, Howells DW, Sena ES, et al. Can animal models of disease reliably inform human studies? PLoS Med. 2010;7:e1000245.

22. Dominici M, Le Blanc $K$, Mueller I, et al. Minimal criteria for defining multipotent mesenchymal stromal cells. The International Society for Cellular Therapy position statement. Cytotherapy. 2006;8:315-7.

23. El Aidi H, Adams A, Moons KG, et al. Cardiac magnetic resonance imaging findings and the risk of cardiovascular events in patients with recent myocardial infarction or suspected or known coronary artery disease: a systematic review of prognostic studies. J Am Coll Cardiol. 2014;63:1031-45.

24. Jansen Of Lorkeers SJ, Eding JE, Vesterinen HM, et al. Similar effect of autologous and allogeneic cell therapy for ischemic heart disease: systematic review and meta-analysis of large animal studies. Circ Res. 2015;116:80-6.

25. van der Spoel TI, Jansen of Lorkeers SJ, Agostoni P, et al. Human relevance of pre-clinical studies in stem cell therapy: systematic review and metaanalysis of large animal models of ischaemic heart disease. Cardiovasc Res. 2011;91:649-58.

26. Emerson M. Refinement, reduction and replacement approaches to in vivo cardiovascular research. Br J Pharmacol. 2010;161:749-54.

27. Cho YH, Cha MJ, Song BW, et al. Enhancement of MSC adhesion and therapeutic efficiency in ischemic heart using lentivirus delivery with periostin. Biomaterials. 2012;33:1376-85.

28. Deten A, Volz HC, Briest W, et al. Cardiac cytokine expression is upregulated in the acute phase after myocardial infarction. Experimental studies in rats. Cardiovasc Res. 2002;55:329-40.
29. Dewald O, Ren G, Duerr GD, et al. Of mice and dogs: species-specific differences in the inflammatory response following myocardial infarction. Am J Pathol. 2004;164:665-77.

30. Hughey $C C$, James FD, Ma L, et al. Diminishing impairments in glucose uptake, mitochondrial content, and ADP-stimulated oxygen flux by mesenchymal stem cell therapy in the infarcted heart. Am J Physiol Cell Physiol. 2014;306:C19-27.

31. Richardson JD, Psaltis PJ, Frost $L$, et al. Incremental benefits of repeated mesenchymal stromal cell administration compared with solitary intervention after myocardial infarction. Cytotherapy. 2014;16:460-70.

32. Ono K, Matsumori A, Shioi T, et al. Cytokine gene expression after myocardial infarction in rat hearts: possible implication in left ventricular remodeling. Circulation. 1998;98:149-56.

33. Khangura S, Konnyu K, Cushman R, et al. Evidence summaries: the evolution of a rapid review approach. Syst Rev. 2012;1:10,4053-1-10.

34. DerSimonian R, Laird N. Meta-analysis in clinical trials. Control Clin Trials. 1986;7:177-88.

35. Henderson VC, Kimmelman J, Fergusson D, et al. Threats to validity in the design and conduct of preclinical efficacy studies: a systematic review of guidelines for in vivo animal experiments. PLoS Med. 2013;10:e1001489.

36. Friedrich $\mathrm{JO}$, Adhikari NK, Beyene J. The ratio of means method as an alternative to mean differences for analyzing continuous outcome variables in meta-analysis: a simulation study. BMC Med Res Methodol. 2008:8:32,2288-8-32

37. Higgins JP, Thompson SG. Quantifying heterogeneity in a meta-analysis. Stat Med. 2002;21:1539-58.

38. loannidis JP, Trikalinos TA. An exploratory test for an excess of significant findings. Clin. Trials. 2007:4:245-53.

39. Hayashino Y, Noguchi Y, Fukui T. Systematic evaluation and comparison of statistical tests for publication bias. J Epidemiol. 2005;15:235-43.

40. Contopoulos-loannidis DG, Ntzani E, loannidis JP. Translation of highly promising basic science research into clinical applications. Am J Med. 2003;114:477-84.

41. Horn J, de Haan RJ, Vermeulen M, et al. Nimodipine in animal model experiments of focal cerebral ischemia: a systematic review. Stroke. 2001;32: 2433-8.

42. Lee DS, Nguyen QT, Lapointe N, et al. Meta-analysis of the effects of endothelin receptor blockade on survival in experimental heart failure. J Card Fail. 2003:9:368-74.

43. Devereaux PJ, Mrkobrada M, Sessler DI, et al. Aspirin in patients undergoing noncardiac surgery. N Engl J Med. 2014;370:1494-503.

44. Devereaux PJ, Sessler DI, Leslie K, et al. Clonidine in patients undergoing noncardiac surgery. N Engl J Med. 2014;370:1504-13.

45. POISE Study Group, Devereaux PJ, Yang H, et al. Effects of extendedrelease metoprolol succinate in patients undergoing non-cardiac surgery (POISE trial): a randomised controlled trial. Lancet. 2008:371: 1839-47.

46. Ashton CM, Petersen NJ, Wray NP, et al. The incidence of perioperative myocardial infarction in men undergoing noncardiac surgery. Ann Intern Med. 1993;118:504-10

47. Fleisher LA, Fleischmann KE, Auerbach AD, et al. 2014 ACC/AHA guideline on perioperative cardiovascular evaluation and management of patients undergoing noncardiac surgery: a report of the American College of Cardiology/American Heart Association Task Force on practice guidelines. J Am Coll Cardiol. 2014;64:e77-137.

\section{Submit your next manuscript to BioMed Central and we will help you at every step:}

- We accept pre-submission inquiries

- Our selector tool helps you to find the most relevant journal

- We provide round the clock customer support

- Convenient online submission

- Thorough peer review

- Inclusion in PubMed and all major indexing services

- Maximum visibility for your research

Submit your manuscript at www.biomedcentral.com/submit 